\title{
A Rare Presentation of Benign Lymphoepithelial Cyst in a Young Child - A Case Report
}

\author{
Gnanavelu Injeti ${ }^{1}$, Maithili Joshi², Amar Taksande³, Revat Meshram ${ }^{4}$ \\ 1,2,3,4 Department of Paediatrics, Jawaharlal Nehru Medical College, \\ Datta Meghe Institute of Medical Sciences, Sawangi (Meghe), Wardha, Maharashtra, India.
}

\section{INTRODUCTION}

Benign lymphoepithelial cyst, is a rare entity, mostly involving the parotid gland or the lateral cervical region which contains lymph nodes. It is formed as a result of cystic dilatation of the ductules triggered due to lymphocytes. They are seen in human immunodeficiency virus (HIV) patients, especially in the parotid gland. It is mainly diagnosed by histopathological examination. Here we report an eight-year-old girl who is human immunodeficiency virus positive has bilateral benign lymphoepithelial cyst (BLC) of parotid gland.

A benign lymphoepithelial cyst is broadly studied as a relevant cause of enlargement of the parotids in human immunodeficiency virus patients. They usually expand to be huge, followed by a physical deformity and facial asymmetry. It is not common and accounts to $3 \%$ of all tumours of salivary glands. The cysts are equally distributed among both genders and usually manifest as a non-tender swelling in the parotid region detached from the facial nerve. Mostly cysts of the salivary glands can occur as a result of rupture of salivary gland ducts, incomplete or total occlusion of the excretory ducts or sluggish flow of saliva in ducts. ${ }^{1-4}$ Here we are discussing a case of benign lymphoepithelial cyst of parotid gland which was diagnosed in an eight-year-old girl who is tested positive for human immunodeficiency virus.

\section{PRESENTATION OF CASE}

A female child, aged 8 years born out of a non-consanguineous marriage had swelling over the parotid and submandibular region. She was tested human immunodeficiency virus positive 5 years ago. Some medication was stared but she stopped taking it and did not return to the hospital for follow up. Her parents are also human immunodeficiency virus positive and not taking any medication. Three years back, she presented with bilateral swelling over the parotid gland. On examination, hepatosplenomegaly was present. Ultrasonography of the bilateral swelling revealed bilateral lymphoepithelial cyst. Bone marrow aspiration was suggestive of micro normoblastic erythropoiesis. Magnetic Resonance Imaging (MRI) report was bilateral enlargement of the parotid gland with well circumscribed cystic lesions associated with submandibular lymphadenopathy which was suggestive of lymphoepithelial cysts. So, the excision of the lymphoepithelial cysts on left side was done followed by histopathological examination, which divulged cyst lined by glandular epithelium consisting of lymphoid follicles were suggestive of benign lymphoepithelial cyst $s$ of the parotid glands. During the immediate post-operative period, she developed left sided facial palsy. Steroid therapy was initiated for the same and child was advised to follow up after a month. Excision on the right side was delayed; due to facial palsy on left side.
Corresponding Author: Dr. Gnanavelu Injeti, Department of Paediatrics, Jawaharlal Nehru Medical College, Datta Meghe Institute of Medical Sciences, Sawangi (Meghe), Wardha, Maharashtra - 442004, India. E-mail: getgnana@gmail.com

DOI: $10.14260 /$ jemds/2021/11

How to Cite This Article:

Injeti $G$, Joshi $M$, Taksande A, et al. A rare presentation of benign lymphoepithelial cyst in a young child - case report. J Evolution Med Dent Sci 2021;10(01):59-61, DOI: $10.14260 /$ jemds/2021/11

Submission 15-09-2020,

Peer Review 10-11-2020,

Acceptance 16-11-2020,

Published 04-01-2021.

Copyright (C) 2021 Gnanavelu Injeti et al. This is an open access article distributed under Creative Commons Attribution License [Attribution 4.0 International (CC BY 4.0)] 
Now again, she presented with huge swelling over the bilateral submandibular region (right $>$ left). She also had low grade fever and decreased appetite. There was no history of ear discharge, rash, vomiting, decreased salivation, altered sensorium, convulsions, or headache. Human immunodeficiency virus antibody was reported positive in the patient and her parents. On local examination, a well-defined swelling was seen on the right lower third of the face below the ear lobule overlying the angle of mandible; was oval in shape and measured approximately $3 \mathrm{~cm} \times 3 \mathrm{~cm}$ in size. On palpation, the swelling was firm, tender and immobile with local rise of temperature, no erythema or any discharge from swelling. She had deviation of the angle of the mouth towards the right side and was unable to close her left eye completely suggestive of lower motor neuron type of facial palsy (Figure 1). On admission she had a temperature of $38.5^{\circ} \mathrm{C}$, a pulse rate of 90 beats / minute, a blood pressure of 100 / $70 \mathrm{mmHg}$, a respiratory rate of 24 breaths / minute and oxygen saturation $98 \%$ in room air. ${ }^{5}$ She had pallor, no cyanosis, clubbing or icterus. On abdominal examination, there was splenohepatomegaly. ${ }^{6}$ Cardiovascular examination was normal. Air entry is bilaterally equal on respiratory system examination. Central nervous system examination revealed no focal neurological deficits. She did not have any meningeal signs or sensory deficit. Fundus examination was done and it was normal. ${ }^{7}$

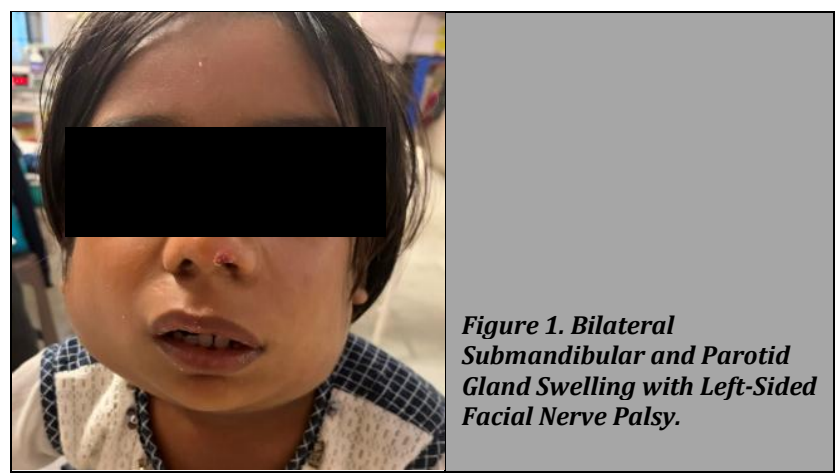

Laboratory tests revealed haemoglobin $8 \mathrm{~g} / \mathrm{dl}$, WBC $12,500 / \mathrm{mm}^{3}$, platelets 2.97 lakh $/ \mathrm{mm}^{3}$, C-reactive protein 51 $\mathrm{mg} / \mathrm{dL}$, serum $\mathrm{Na}+138 \mathrm{mmol} / \mathrm{l}$, serum potassium $3.5 \mathrm{mmol}$ / l, bicarbonate $27 \mathrm{mmol} / \mathrm{l}$, blood urea $14 \mathrm{mg}$ / dL and serum creatinine $0.7 \mathrm{mg} / \mathrm{dL}$. Serum albumin was $3.4 \mathrm{~g} / \mathrm{dL}$, globulin $11 \mathrm{~g} / \mathrm{dL}$, and lactate dehydrogenase (LDH) $267 \mathrm{U} / \mathrm{l}$. An ultrasonography of the involved region was done which s / o lymphoepithelial cyst. An aspiration was done from the swelling using a wide bore needle, which showed the presence of a straw-coloured fluid. The aspirated fluid subjected for fine-needle aspiration cytology (FNAC), which revealed the presence of lymphocytes, few histiocytes, few plasma cells and squamous cells dispersed in a proteinaceous material. A biopsy of the lymph node was done which was inconclusive. ${ }^{8}$

By imaging of the neck by magnetic resonance, we viewed hyperintense fluid in the cysts in both T1 - and T2-weighted images with visibly huge bilateral parotid glands accompanying submandibular lymphadenopathy likely denoting bilateral benign lymphoepithelial cysts.

\section{DISCUSSION OF MANAGEMENT}

Oral antibiotics and analgesics were given to the child. She was advised to resume her anti-retroviral medications which were irregularly taken earlier and follow up after a month to see for any clinical deterioration. The parents were not willing for excision of the right sided cyst.

\section{DISCUSSION}

Benign lymphoepithelial cysts or the branchial cysts are the non-malignant, slowly expanding lesions that occur more commonly in adults with a gender predilection of $60-80 \%$ in females. ${ }^{3}$ Maximum parotid benign lymphoepithelial cysts are seen in retro positive population where they commonly involve on both sides. Their etiopathogenesis is occlusion of the ducts secondary to cellular proliferation, reactive lymphoproliferation occurs in the lymph nodes or occur as a result of damage to the salivary gland ducts. Different types of cysts can be found within the parotid gland including conventional cysts, congenital cleft cysts (lymphoepithelial cyst which may also be associated with acquired immunodeficiency syndrome), dysgenetic polycystic disease of the salivary glands and salivary gland tumours with cystic presentation. Benign lymphoepithelial cyst (BLEC) typically presents with bilateral parotid enlargement that generally consists of multiple cysts in one gland. These painless cysts grow slowly and are soft, often fluctuant. These cysts are not locally invasive and have virtually no malignant potential but can cause significant local disfiguration. The lymphoepithelial cysts may grow to reach considerable sizes enough to cause facial deformities. The other diseases which mimic benign lymphoepithelial cyst consists of intramuscular benign haemangioma (IMH), Warthin's tumour and lymphoma. As a part of a diffuse infiltrative lymphocytosis syndrome, most of them have been associated with human immunodeficiency virus infection. Among the human immunodeficiency virus positive patient, 3 - $10 \%$ cases have incidence of human immunodeficiency virus - associated salivary disease. ${ }^{4}$ Such presentation is uncommon in paediatric population. Involvement of salivary glands occurs before acquired immunodeficiency syndrome and might be the first sign of human immunodeficiency virus infection. It was earlier studied that salivary elements stagnated within hyperplastic intra parotid lymph nodes become hyperplastic on their own, leading to epithelial proliferation and evolution of a cyst. This theory is anchored by pathologic references that most lymphoepithelial cysts occur within intra parotid lymph nodes. ${ }^{9}$

It is diagnosed after studying the case history, detailed examination and histopathological examination. Diagnostic modalities which avoid invasion are ultrasonography, computed tomography scan and magnetic resonance imagingwhich aptly denote numerous thin-walled cysts along with diffuse lymphadenopathy of the cervical region. Invasive modalities for diagnosis comprise of fine needle aspiration cytology and biopsy of the glandular tissue. 
Fine needle aspiration cytology of benign lymphoepithelial cyst commonly consists of heterogeneous cells, along with spread out foamy macrophages and anucleated squamous cells in a proteinaceous backdrop. The peculiar histopathologic pattern is squamous or glandular epitheliumlined cleft enclosed by profuse lymphoid tissue with demarcated germinal centers. ${ }^{10}$ Normal parotid tissue is replaced by lymphoid tissue, and the follicles are larger and irregularly shaped than unreactive follicles in normal lymph nodes. The germinal centres have large number of macrophages, and some of them have a weakened mantle of tiny lymphocytes that penetrate into the follicles. Human immunodeficiency virus patients with benign lymphoepithelial cysts are highly predisposed to develop lymphomas and thus need strict observation and hospital visits. Management of the lymphoepithelial cyst consists of both conservative as well as surgical approach. Conservative approach includes decompression of the cyst by aspiration of the fluid thereby reduction of the pressure. It should be thought of in a patient like human immunodeficiency virus positive, whose immune status is hampered and in which the surgery is easily outweighed by the risk. Other conservative treatment includes radiation therapy. The definitive treatment is total enucleation of the cyst along with removal of the affected gland. Most of them are totally treated by surgery and may not get a recurrence in their lifetime. Other options include aspiration and drainage, radiation therapy, sclerotherapy and excision.

\section{CONCLUSIONS}

Benign lymphoepithelial cysts can present as cystic parotid swellings even in children with a poor immune status. These are rarely malignant, but they can aggressively turn so. For a child with any neck mass, human immunodeficiency virus test should be done to know if it is the underlying cause of lymphoid hyperplasia. Enucleation of cyst with a portion of unaffected tissue forms the crux of management in these patients.

Financial or other competing interests: None.

Disclosure forms provided by the authors are available with the full text of this article at jemds.com.

\section{REFERENCES}

[1] Rahman SA, Shaari R, Hassan R. Parotid lymphoepithelial cyst: a case report. Archives of Orofacial Sciences 2006;1:71-5.

[2] Alves CA, Ribeiro Júnior O, Borba AM, et al. Parotid lymphoepithelial cyst in non - human immunodeficiency virus patient. J Clin Exp Dent 2011;3(Suppl 1):e400-3.

[3] Harry IL. Lymphoid hyperplasias and lymphomas of salivary glands. Pathology Case Reviews 2004;9(5):20613.

[4] Carnelio S, Chandramouli M, Rodrigues G. Parotid lymphoepithelial cyst in a human immunodeficiency virus - negative individual: a case report. Iran J Med Sci 2018;43(6):668-70.

[5] Pillai S, Agarwal AC, Mangalore AB, et al. Benign lymphoepithelial cyst of the parotid in human immunodeficiency virus negative patient. J Clin Diagn Res 2016;10(4):MD05-6.

[6] Mandel L, Hong J. human immunodeficiency virusassociated parotid lymphoepithelial cysts. J Am Dent Assoc 1999;130(4):528-32.

[7] Glosser JW, Pires CAS, Feinberg SE. Branchial cleft or cervical lymphoepithelial cysts: etiology and management. J Am Dent Assoc 2003;134(1):81-6.

[8] Panchbhai AS, Choudhary MS. Branchial cleft cyst at an unusual location: a rare case with a brief review. Dentomaxillofac Radiol 2012;41(8):696-702.

[9] Joshi J, Shah S, Agarwal D, et al. Benign lymphoepithelial cyst of parotid gland: review and case report. J Oral Maxillofac Pathol 2018;22(Suppl 1):S91-7.

[10] Salah T, Eltohami YI, Halawi A, et al. Case report of a parotid benign lymphoepithelial cyst. Adv Dent \& Oral Health 2020;12(3):555836. 